\title{
TROPAS DE PARDOS E DE PRETOS EM SÃO PAULO COLONIAL: A RECRUTA GRANDE (1765-1777)
}

\author{
Fernando Prestes de Souza \\ Orientação: Luiz Geraldo Silva
}

PALAVRAS-CHAVE: Homens livres de cor; recrutamento militar; mobilidade social.

O fim da União Ibérica, em 1640, instou Portugal e Castela a se colocarem como reinos independentes. A demarcação dos limites entre as Américas portuguesa e hispânica revelou-se marcada por tensões de toda ordem, e, não obstante a promulgação de tratados bilaterais, estes territórios - em especial os da bacia platina permaneceram em disputa até a primeira metade do século XIX. Com a Guerra dos Sete Anos na Europa, entre 1756-1763, na qual ambos encontravam-se em lados opostos, Portugal foi invadido por uma coalizão franco-espanhola. Do outro lado do Atlântico, paralelamente, a Colônia do Sacramento foi assaltada por forças espanholas, bem como alguns territórios do Rio Grande do Sul. Tinha inicio em 1762, desse modo, uma guerra que duraria até 1777 e para a qual a coroa lusitana mobilizaria homens e capitais das várias partes de seu império. Em 1763 a capital do Brasil mudou de Salvador para o Rio de Janeiro, e já em 1765 a capitania de São Paulo foi restaurada, posto que estava subordinada ao Rio de Janeiro desde 1748. Estas medidas estavam relacionadas, de alguma forma, à estratégia de guerra, a qual tinha como base a ação conjunta entre Rio de Janeiro, Minas Gerais e São Paulo para a defesa das partes meridionais da América portuguesa. ${ }^{1}$ Nestas três unidades políticoadministrativas foi empreendida ampla reestruturação militar, com destaque para o tamanho e intensidade do recrutamento. Tendo em vista esta grande militarização, a presente monografia teve como

${ }^{1}$ MAXWELL, Kenneth. Marquês de Pombal: paradoxo do iluminismo. Rio de Janeiro: Paz e Terra, 1997. 
tema o recrutamento militar de homens de cor em São Paulo, entre 1765 e 1777, para a guerra luso-castelhana. As principais discussões deste trabalho giraram em torno da presença de pardos e mulatos na reestruturação militar paulista e na guerra luso-castelhana; da forma do recrutamento militar; do exercício de controle social e possibilidades de mobilidade social mediante enquadramento nas tropas; da associação entre o exercício de uma função militar e atividades comerciais; das fugas e deserções; e da resistência dos brancos à sua incorporação em tropas mistas.

O magnífico conjunto de fontes contido nos Documentos Interessantes Para a História e Costumes de São Paulo, onde se encontram transcritas milhares de correspondências ativas e passivas dos governadores e capitães-generais de São Paulo, foi a base documental para a pesquisa. Do mesmo modo, utilizaram-se manuscritos do Arquivo Histórico Ultramarino do Projeto Resgate, bem como diversas cartas publicadas por Marcos Carneiro de Mendonça, em Século XVIII, século pombalino no Brasil. ${ }^{2}$ A partir da leitura destas correspondências foi possível notar um grande esforço das autoridades de São Paulo para enquadrar em corpos militares os homens de cor, e, igualmente, verificar alguns casos de complexa negociação entre governadores coloniais e capitães pardos. Estes aspectos, que envolvem tanto a inserção quanto a mobilidade social ascendente propiciada a negros e pardos na referida capitania, foram muito pouco notados pela historiografia. Talvez porque as informações a esse respeito apareçam de modo muito fragmentado na documentação, acompanhando o fato de que as tropas de pardos eram listadas à parte e não se incluíam em terços à época da guerra, ou, até mesmo, pela dificuldade em classificar coisas provisórias, muitas vezes feitas aos atropelos.

A monografia está estruturada em três capítulos, cada qual dividido em quatro tópicos. O capítulo inicial foi direcionado a

2 MENDONÇA, Marcos Carneiro de. Século XVIII, século pombalino no Brasil. Rio de Janeiro : Xerox do Brasil, 1989. 
apresentar o contexto no qual operou-se o recrutamento de homens de cor em São Paulo. Em primeiro lugar, coube mostrar a organização militar da América portuguesa no século XVIII. Para se compreender a guerra luso-castelhana de 1762-1777 foi necessário discorrer sobre a indefinição das fronteiras na bacia do Prata desde o fim da União Ibérica, em 1640, apontar para as formas e os motivos da política portuguesa naquela região, bem como relacionar as tensões diplomáticas na Europa, na década de 1760, ao agravamento dos conflitos nas partes Meridionais da América portuguesa. Em seguida buscou-se sintetizar a reestruturação militar da capitania em questão e as estratégias de guerra desenvolvidas por Portugal, desde a mobilização em termos imperiais até o plano de ação conjunta envolvendo São Paulo, Minas Gerais, e encabeçado pelo Rio de Janeiro. A análise da carta régia de 22 de março de 1766 que vinha a esclarecer que todos os indivíduos capazes de levantar armas eram passiveis de ser recrutados foi essencial para os fins deste trabalho.

Já o segundo capítulo destinou-se ao exame de aspectos relacionados à presença dos homens de cor, livres ou escravos, em São Paulo, além de contemplar a estratégia de oficiais pardos em melhorar sua posição social mediante institucionalização da tropa. Foi necessário, então, reunir dados numéricos acerca da população da capitania para observar o peso quantitativo dos grupos de escravos e livres ou forros em relação ao conjunto dos habitantes. Ora, objetivou-se averiguar as ligações entre o tráfico de escravos, a disponibilidade de homens de cor livres para ingressar nas tropas, e a formação destas companhias militares. Intentou-se, também, informar algo sobre a visão depreciativa que as autoridades mantinham a respeito destes sujeitos e a partir daí estabelecer o contraste com os discursos exultando o alistamento dos sertanejos paulistas. Em seguida indicou-se alguns pontos de vista na historiografia concernentes às possibilidades de ascensão social aos negros da América portuguesa, numa configuração social na qual estes grupos eram visivelmente mais discriminados que outros. Este percurso levou a análise de casos em que homens de cor de São 
Paulo se beneficiaram neste momento de efervescência militar para elevar-se socialmente e afastar-se das máculas próprias à sua raça existentes no século XVIII.

O terceiro capítulo foi encaminhado para a discussão de aspectos respeitantes a presença dos homens de cor na estrutura militar paulista entre 1765-1777. Houve um esforço em mapear as companhias militares compostas por livres de cor e em compreender os papéis atribuídos aos cativos neste contexto. As fontes indicaram, ademais, que o recrutamento servia eficazmente à resolução de problemas internos. Delineou-se, então, uma perspectiva distinta daquela sobre as possibilidades de mobilidade social aos negros, ou seja, chamou-se atenção para as formas e os objetivos do recrutamento. Daí as seções dedicadas à relação entre recrutamento e controle social, e outra sobre o recrutamento forçado. Destacou-se ainda a inclusão de homens de cor em companhias militares não específicas para negros.

Trilhado este longo caminho, algumas hipóteses e resultados podem ser esboçados. Os homens de cor de São Paulo participaram ativamente da guerra luso-castelhana, mobilizados para a defesa da capitania, em serviço na longínqua fortaleza do Iguatemi - próxima do Paraguai - e foram mesmo instados a combaterem no Rio Grande. Homens e mulheres livres de cor representavam cerca de $20 \%$ da população total de São Paulo em 1772, estimada em 110 mil indivíduos. Com efeito, a partir do último quartel do século XVIII o tráfico de escravos para a referida capitania intensificou-se, paralelamente ao cultivo do açúcar. Tal como a camada social formada por cativos, aquela constituída por forros e negros livres crescia ainda mais. Constatou-se uma distorção na pirâmide etária por conta do reduzido número de pessoas no grupo de homens entre 15 e 60 anos, justamente em idade de serviço militar. O recrutamento militar e as fugas e deserções contribuíram para que estes homens não aparecessem nas listas de população. Membros de companhias de auxiliares e de ordenanças empreendiam verdadeiras caças a desertores, que, muitas vezes associados a escravos fugidos, 
permaneciam arranchados "nos matos", ou "aquilombados". Nesta conturbada época, até mesmo os familiares de homens que fugiam ao recrutamento eram presos, sobretudo suas mães e esposas. O enquadramento em corpos militares funcionava como mecanismo de controle social, fosse por inculcar nos indivíduos a disciplina militar, fosse por retirar da sociedade os maus vassalos, conduzindo-os para regiões onde fossem militarmente úteis.

Havia corpos militares formados exclusivamente por homens de cor, e inclusive uma espécie de "exército de reserva" formado por cativos armados com lanças para operar em situações de emergência. Notou-se também que muitos homens de cor eram inseridos em tropas mistas, ao lado de brancos e índios. Nos momentos mais tensos para os portugueses, entre 1776 e 1777, quando se previa o ataque a Santa Catarina e invasões ao litoral paulista, formaram-se várias companhias com esta composição mista. Logo apareceram resistências de brancos que se indignavam por servir ao lado de negros. Estas reclamações, porém, não foram atendidas pelo capitãogeneral Martim Saldanha. Parece mesmo que os improvisos marcaram este esforço de guerra, pois também homens doentes, com bócio, foram incluídos nas tropas. No Iguatemi é que predominaram os soldados pardos e mulatos, servindo em tropas irregulares chamadas Aventureiros. Embora o nome de muitas delas não se referisse a cor de seus componentes, no Diário da viagem de José Custódio de Sá e Faria, de 1775, consta que "tiradas as duas companhias de tropa de infantaria, as mais são compostas de negros, mulatos e criminosos, que têm pouco que perder, e a quem a honra não interessa e só a conveniência pôde obrigar". ${ }^{3}$ Aqui, pode-se perfeitamente substituir a palavra "conveniência" por "força". Outro era o caráter da tropa de pardos de Santos. Examinou-se a negociação entre o capitão pardo Caetano Francisco Santiago e o

\footnotetext{
${ }^{3}$ Cf. "Diário da viagem que fez o brigadeiro José Custódio de Sá e Faria da Cidade de São Paulo à Praça de Nossa Senhora dos Prazeres do rio Iguatemy (17741775)". In: Revista do Instituto Histórico e Geográfico Brasileiro. Tomo 39, 1876, p. $218-219$.
} 
governador morgado de Mateus visando formação desta companhia. $\mathrm{O}$ interesse de Santiago, ao contrário do que se disse daqueles soldados do Iguatemi, certamente era gozar dos mesmos privilégios previstos aos oficiais militares pela carta régia de 22 de março 1766 , ou seja, o capitão pardo buscava apresentar-se à sociedade com as mesmas honras que um oficial militar das tropas pagas. Cruzando algumas fontes, foi possível ver que este indivíduo, bem como o tenente dos pardos daquele batalhão, esteve envolvido em altos negócios comerciais na vila de Santos, paralelamente ao exercício de suas funções militares. Sem dúvida procuravam consolidar uma posição social de destaque, já obtida graças a atividades comerciais, através da aquisição de honras militares. Estes homens eram poucos em relação ao restante dos homens de cor de São Paulo, ou uma elite dentre eles.

O número relativamente reduzido destes sujeitos certamente teve correspondências no caráter das companhias militares nas quais foram enquadrados. Do mesmo modo, considerou-se aqui que o recrutamento militar em situação de guerra não somente poderia reproduzir as condições e divisões sociais, mas, de outro ponto de vista, propiciar mudanças. Estas, se foram apenas provisórias ou se construíram duradouros padrões de inserção social para os homens livres de cor, só podem ser apreendidas mediante ampliação do recorte temporal desta pesquisa, o que de fato será proposto em um futuro projeto para o mestrado. 